\title{
Strategien mot sosioøkonomiske helseulikheter: Skal den innbefatte helserelatert seleksjon?
}

\author{
Jon Ivar Elstad \\ Norsk institutt for forskning om oppvekst, velferd og aldring (NOVA), Oslo \\ Adresse for korrespondanse: Jon Ivar Elstad, NOVA, Pb 3223 Elisenberg, 0208 Oslo \\ Telefon: 22541288 Telefax: $22541201 \quad$ E-post: Jon.I.Elstad@nova.no
}

\begin{abstract}
SAMMENDRAG
Erkjennelsen om at sosioøkonomiske helseulikheter både er et rettferdighetsproblem og et folkehelseproblem er økende. I hovedsak blir sosioøkonomiske helseulikheter forstått som et resultat av hvordan helseskadelige sider ved miljø og levesett varierer mellom sosiale lag (sosial kausalitet). Imidlertid kan selektive prosesser også bidra. Slike prosesser skyver de med gode helseressurser oppover i den sosiale lagdelingen, mens de med helseproblemer oftere får lavere utdanning og mindre tilfredsstillende yrkeskarrierer. Artikkelen oppsummerer forskningsresultater når det gjelder slike selektive prosesser. Alt i alt er kausalitets-forklaringen utvilsomt mest relevant, men selektive prosesser spiller også inn, særlig i overgangsfasen mellom ungdom og tidlig voksenkarriere og i avgang fra yrkeslivet seinere i livsløpet. Artikkelen konkluderer med at disse selektive prosessene også må være et angrepsmål for den helsepolitiske strategien mot sosioøkonomiske helseulikheter.
\end{abstract}

Elstad JI. Should strategies to combat socioeconomic inequalities in health include health selection? Nor J Epidemiol 2002; 12 (1): 39-42.

\section{ENGLISH SUMMARY}

Socioeconomic inequalities in health are widely recognised as a problem both for social justice and population health. Strategies to combat these inequalities are mainly governed by the social causation explanation which assumes that these inequalities arise as a consequence of social differences in environments and lifestyles. The health selection explanation, which assumes that good health resources enhance upward social mobility while health problems predispose for less educational and occupational success, constitutes an opposing understanding. The article reviews some research results about healthselective mobility. Health selection is observed especially in the transition from adolescence to work career as young adults, and in transitions into and out of the work force during adult careers. Moreover, exits from occupational careers in middle age to pre-retirement or disability pension are strongly health-related. The overall effects of such selective processes in creating socioeconomic health inequalities are generally judged to be modest. Nevertheless, they should not be neglected when considering strategies against socioeconomic health inequalities. Today, health-selective processes constitute a contributing factor to these inequalities, and if current efforts to reduce social variations in environments are successful, paradoxically the role of health-selective processes may emerge as more important in the future. It is suggested that Norway should follow the lead of the Netherlands which explicitly have included healthselective processes as a target in their strategy for reducing socioeconomic health inequalities.

\section{SOSIOØKONOMISKE HELSEULIKHETER, KAUSALITET OG SELEKSJON}

De med høy yrkesstatus, høy inntekt og høy utdanning har systematisk lengre levealder og mer sykdomsfrihet enn de som er lavere plassert i samfunnets sosiale lagdeling [1-4]. Disse sosioøkonomiske helseulikhetene representerer et rettferdighetsproblem og et folkehelseproblem og har lenge vært på den internasjonale helsepolitiske dagsorden [5]. Helsepolitiske initiativer for å begrense disse helseulikhetene har i det store og hele vært styrt av sosial kausalitets-forklaringen. Kjernen i denne forklaringen er at ulikhetene oppstår på grunn av sosiale variasjoner $\mathrm{i}$ eksponering for helseskadelige omgivelser, der arbeidsmiljø og arbeidsbelastninger, manglende materielle ressurser, ernæringskvalitet og boligstandard, tilgang til helsetjenester, røyking, mosjon og annen helseatferd, og psykososialt miljø regnes som viktige faktorer. Kausalitets-forklaringen antar altså at forskjellene i typiske omgivelser og levesett mellom sosiale lag forårsaker ulikheten i helseprofiler. Den overordnete strategi for å begrense sosioøkonomiske helseulikheter er derfor å utjevne de relevante forskjellene i miljø og levesett. I praksis tar dette form av intervensjoner for å minske omfanget av helseskadelige omgivelser - av skadelige arbeidsforhold, materiell deprivasjon, usunn livsstil, osv. Ved å angripe disse sykdomsframkallende miljøfaktorene, som er over- 
representert i lavere sosiale lag, vil de sosiale variasjonene $i$ helserelevante omgivelser minske, og det forventede resultatet er en utjevning av helseulikhetene.

Det finnes imidlertid en annen forklaring på de sosioøkonomiske helseulikhetene som gjerne kalles seleksjons-forklaringen. Den antar at selektive prosesser gjennom livsløpet favoriserer de med bedre helse (eller bedre helsepotensiale), slik at de oppnår større framgang i utdanning, yrkeskarrierer og inntekt. De som rekrutteres inn $\mathrm{i}$ de høyere sosiale lagene har derfor en gunstigere helseprofil. En variant av samme forklaring er "drift-hypotesen", som innebærer at de med helsesvikt vil ha en tendens til å synke i det sosiale hierarkiet over tid, ettersom deres helseproblemer virker negativt på muligheten for arbeid, karriere og inntekt. Via slike prosesser vil høyere sosiale lag befolkes i større grad av dem med god helse, mens de lavere sosiale lagene får et større innsig av personer med helseproblemer. Kausalitets-forklaringen forstår de sosioøkonomiske helseulikhetene som en konsekvens av hvilke omgivelser de sosiale lag eksponeres for, mens seleksjons-forklaringen forstår derimot disse helseulikhetene som en konsekvens av hvem de ulike sosiale lagene "eksponeres" for.

\section{ER STRATEGIEN BASERT PÅ KAUSALITETS- FORKLARINGEN TILSTREKKELIG?}

Strategien med å utjevne miljøforskjellene mellom sosiale lag er utvilsomt viktig. Vellykkete intervensjoner vil både minske de sosioøkonomiske helseulikhetene og dessuten ha positive helsekonsekvenser for befolkningen. Seleksjons-forklaringen reiser likevel et spørsmål om strategien basert på kausalitets-forklaringen er tilstrekkelig. I teorien kan vi tenke oss at de sosioøkonomiske helseulikhetene kan vedvare selv om miljøforskjellene reduseres. Seleksjons-forklaringen knytter seg nemlig ikke til forskjeller i miljø, omgivelser og levesett mellom de sosiale lagene, men derimot til de prosessene som påvirker plasseringen i den sosiale lagdelingen.

Seleksjons-forklaringen fokuserer på sosial mobilitet og hvordan folk beveger seg mellom de sosiale lagene gjennom livsløpet. Dersom karrierene i utdannings-, yrkes- og inntektshierarkiene er sterkt relatert til helse, direkte eller indirekte, vil dette kunne generere sosioøkonomiske helseulikheter. Hypotetisk kan vi derfor konfronteres med en situasjon der miljøulikhetene ikke lenger er av særlig helsemessig betydning, men de sosioøkonomiske helseulikhetene vil likevel produseres på nytt og på nytt, som en følge av de selektive mekanismene som skyver folk med god helse oppover i de sosiale lagene og folk med dårlig helse nedover i de sosiale hierarkiene.

\section{HELSESELEKSJON GJENNOM LIVSLØPET}

Hvor viktige er slike selektive mekanismer i dagens samfunn? Dette har lenge vært et tema i helseulikhetsforskningen. Resultatene peker i følgende retning.
I ungdommen er utdanningsvalget ofte startblokka for hvilke livsbaner en følger seinere i livet. Alvorlige sykdommer og funksjonshemninger kan hindre utdanningsvalg eller forsinke utdanningsforløpet [6]. Direkte diskriminering eller simpelthen praktiske vansker for dem med helseproblemer kan svekke utdanningskarrieren. En mer indirekte form for selektive prosesser er også påvist. Finske og engelske undersøkelser har vist en sammenheng mellom helseatferd og utdanningsvalg i tenårene [7-9]. Selv når en kontrollerer for sosial bakgrunn, finner en mer usunn livsstil blant dem som avslutter utdanningen tidlig eller velger kortere og mer praktisk orienterte utdanninger. Slike subtile prosesser, der ungdom som ikke lykkes i krevende utdanninger og derfor disponeres for mindre framgang $i$ yrkeslivet samtidig utvikler mer helseskadelig atferd, er en form for indirekte seleksjon som genererer en sammenheng seinere i livet mellom helsesvikt og lav plassering i den sosiale lagdelingen.

En tilsvarende kritisk fase i livsløpet er inntreden i yrkeslivet som ung voksen. Her kan selektive prosesser gi dem med helseproblemer eller et mindre bra helsepotensiale en oppstart i yrkeslivet som leder mot mindre tilfredsstillende yrkeskarrierer. Avismeldinger rapporterer om at arbeidsgivere helst vil unngå å ansette personer som de vet har høyt sykefravær, og dessuten kan de reagere negativt mot både overvekt og røyking. Slike diskriminerende praksiser anvendes neppe strikt, men når de utspiller seg i et stort antall ansettelsesprosesser, akkumulerer de seg til en tendens som skyver de med faktiske eller potensielle helseproblemer mot de mindre attraktive delene av arbeidsmarkedene. Også selv-seleksjon kan spille inn ved at helseproblemer svekker mot og selvtillit og bidrar til at de som føler at helsa er et problem staker ut mindre dristige yrkeskarrierer [10]. For unge kvinner er det observert en tendens til at mindre bra helse som elev eller student henger sammen med større tendens til å være hjemmearbeidende eller bare i deltidsarbeid i midten av 20-årsalderen [11].

De prosessene som etablerer unge i yrkeshierarkiet er imidlertid av mange typer. For visse manuelle lavstatusyrker vil arbeidsgivere favorisere solid fysisk helse, og rekrutteringen av unge til slike yrker kan i noen grad være positivt selektert. Det overordnete er likevel at selektive prosesser i overgangsfasen mellom ungdom og voksen, knyttet til utdanningsveier og den tidlige yrkeskarrieren, bidrar til at mønsteret av sosioøkonomiske ulikheter i helse blir etablert allerede i 20 årsalderen [12].

Gjennom voksenlivet er relasjonene mellom yrkeskarrierer og helse sammensatt. Et funn som går igjen i en rekke undersøkelser er at helseforhold spiller liten rolle for hovedtrekkene i de fleste yrkeskarrierer [1317]. Blant dem som er yrkesaktive gjennom hele det voksne livsløpet finner en bare små tendenser til mindre oppadgående yrkesmessig mobilitet og mer "drift" nedover i yrkeshierarkiet blant dem som rapporterer udramatiske helseproblemer. En viktig grunn til dette er at i vår type samfunn er yrkeskarrierene sterkt insti- 
tusjonalisert og så knyttet til utdanning, kompetanse og yrkeserfaring, at de mindre helsevariasjonene blant dem som fungerer $\mathrm{i}$ arbeidslivet ikke er en vesentlig kilde til hva slags posisjoner en inntar i den sosiale lagdelingen. Likevel finner en også helse-relaterte seleksjonsprosesser i den voksne yrkeskarrieren, men de er først og fremst knyttet til bevegelser ut av og inn i arbeidsmarkedet. Helseproblemer kan svekke arbeidstilknytningen og dermed generere en sammenheng mellom dårlig helse og lav inntekt, ettersom inntektsnivået i så sterk grad avhenger av arbeidsaktivitet [18]. Risikoen for å oppleve episoder med arbeidsløshet er større for dem med helseproblemer, og blant de som er blitt arbeidsledige varierer sjansen for nytt arbeid med helsetilstanden [19-20]. Studier antyder også at blant dem med fysisk krevende manuelle yrker kan helseproblemer utløse overgang til lavere funksjonæryrker - en såkalt "healthy worker effect" som innebærer at bare de med solid fysisk helse kan fortsette $i$ yrker som stiller store krav til fysisk kapasitet [21].

Den mest typiske helserelaterte seleksjonsprosessen blant voksne i moden alder er imidlertid den som fører folk med helseproblemer ut av arbeidslivet, via tidlig pensjonering og uføretrygd. Dette er en offentlig regulert seleksjonsmekanisme, som på den ene siden er en del av velferdsstatens sikkerhetsnett, men som på den annen side virker sterkt $\mathrm{i}$ retning av å plassere de med helseproblemer utenfor yrkeslivet og inn i lavere inntektssjikt. Omfanget av denne ordningen er betydelig. I Norge i 1997 var for eksempel omlag en sjettedel av befolkningen 50-59 år uføretrygdet, og så mye som en tredel av alle i alderen 60-64 år [22]. En konsekvens av slike prosesser er at arbeidslivet, spesielt for de middelaldrende og de som nærmer seg vanlig pensjonsalder, først og fremst blir en arena for dem med mindre helseproblemer. Den helsemessige seleksjonen ut av arbeidslivet fører til en polarisering av helseforholdene. De største skillene går mellom de yrkesaktive og de som står utenfor arbeidsmarkedet. Samtidig er det observert tendenser til relativ beskjedne sosioøkonomiske helseulikheter mellom de yrkesaktive, som en konsekvens av at seleksjonen ut av arbeidslivet har blitt sterkere [23-25]. Uførepensjoneringen er dessuten sosialt selektiv i den forstand at pensjoneringsratene er høyere jo lavere en har befunnet seg i yrkeshierarkiet, og dette bidrar også til reduserte sosioøkonomiske helseulikheter blant de yrkesaktive. De underliggende sosioøkonomiske helseulikhetene framgår imidlertid når en inkluderer ikke nåværende yrkesaktive i analysematerialet, klassifisert etter deres tidligere yrkesposisjoner [23].

I ulike stadier av livsløpet finner en altså selektive prosesser som tenderer mot å generere en sammenheng mellom helsesituasjon og plassering i den sosiale lagdelingen. De opptrer særlig ved inngangen til yrkeslivet via utdanningsveier og startposisjoner i yrkeskarrieren, og ved overganger ut av og inn i arbeidslivet gjennom livsløpet, i særdeleshet mot slutten av yrkeskarrieren der helseproblemer er sterkt involvert i de prosessene som fører til tidligpensjonering og uføretrygd.

\section{BØR STRATEGIEN MOT HELSEULIKHETER INKLUDERE SELEKSJONSPROSESSENE?}

$\AA$ kalkulere den totale effekten av slike selektive prosesser for omfanget av helseulikhetene er innviklet [26]. Den rådende konklusjonen er likevel at disse selektive prosessene, selv om de bidrar, ikke er de mest vesentlige. Sosial kausalitet er alt i alt langt mer dominerende i produksjonen av sosioøkonomiske helseulikheter [13,27-28]. Det paradoksale er imidlertid at seleksjons-forklaringen kan bli mer relevant om helsepolitikken makter å utjevne den sosiale ulikheten $\mathrm{i}$ helseskadelige omgivelser og levesett. I så fall vil kausalitets-forklaringen minske i betydning. Samtidig vil de selektive prosessene spille ut sin virkning uten å være overskygget av effektene fra sosial kausalitet, og de vil derfor framtre som en mer viktig årsak til sosioøkonomiske helseulikheter.

Dette tilsier at når helsepolitikkens mål er å minske de sosioøkonomiske helseulikhetene, kan heller ikke de helse-selektive prosessene være uviktige - selvsagt ikke til fortrengsel for arbeidet med å utjevne miljøforskjeller, men i tillegg. Dette reiser imidlertid mange spørsmål, både om hvilke samfunnsområder helsepolitikken skal inkludere som sitt interesseområde, og dessuten om hvordan en bedømmer selektive prosesser politisk og moralsk. Ifølge en definisjon er helsepolitikkens målsetning å avskaffe sosioøkonomiske helseforskjeller i den grad de er unødvendige, unngåelige og urettferdige [29-30]. De selektive prosessene innebærer at individuelle helsemessige ressurser, både $\mathrm{i}$ form av manifeste helseproblemer og funksjonshemninger og $\mathrm{i}$ form av egenskaper relatert til helsepotensiale som røyking og overvekt, har negative konsekvenser for utdanningsnivå, yrkeskarrierer og inntekt. Er dette unødvendig, unngåelig og urettferdig? Det vil eksistere oppfatninger om at for eksempel næringslivets effektivitetskrav og konkurransejag legitimerer selektive kriterier når det gjelder hvem som skal ansettes, hvem som skal gis opprykk, og hvem en ønsker ut av arbeidsstokken på grunn av helsesvikt. Det er likevel stor grunn til å fastholde at slike selektive prosesser, i hvert fall i mange tilfelle, dreier seg om dels usaklige diskriminerende praksiser og dels om manglende tilrettelegging av utdanningsinstitusjoner og arbeidsbetingelser. Derfor er de ofte verken nødvendige, uunngåelige eller rettferdige.

I noen grad er slike selektive prosesser et tema $\mathrm{i}$ dag, fra tiltak for å bedre tilgjengelighet for funksjonshemmede i utdanningsinstitusjoner til kampanjer for å inkludere sykdomsrammede i arbeidslivet [31]. At de nåværende tiltakene er tilstrekkelig, er imidlertid mer enn tvilsomt. De bør styrkes, ikke bare i lys av sosialpolitiske behov, men også som del av en omfattende strategi mot sosioøkonomiske helseulikheter. Dette skjer i andre land, for eksempel i Nederland, der "Reduksjon av negative konsekvenser av helseproblemer for utdanning, yrkesstatus og inntekt" er et eksplisitt mål i arbeidet mot sosioøkonomiske helseulikheter [32]. Norsk helsepolitikk henger etter, men hvor lenge? 


\section{REFERANSER}

1. Dahl E, Elstad JI. Recent changes in social structure and health inequalities in Norway. Scand J Public Health 2001 (Supplement 55): 7-17.

2. Lahelma E, et al. Health inequalities in the Nordic countries from the 1980s to the 1990s. Scand J Public Health 2001 (Supplement 55).

3. Kunst A. Cross-national comparisons of socio-economic differences in mortality. 1997, Rotterdam: Erasmus University, Thesis.

4. Cavelaars AEJM, et al. Morbidity differences by occupational class among men in seven European countries: An application of the Erikson-Goldthorpe social class scheme. Int J Epidemiol 1998; 27 (2): 222-30.

5. Dahlgren G, Whitehead M. Policies and strategies to promote equity in health. Copenhagen: World Health Organization, Regional Office for Europe, 1992.

6. Grue L. Motstand og mestring. Om funksjonshemning og livsvilkår. Oslo: Abstrakt Forlag, 2001.

7. Glendinning A, Shucksmith J, Hendry L. Social class and adolescent smoking-behavior. Soc Sci Med 1994; 38 (10): 1449-60.

8. Koivusilta L, Rimpela A, Rimpela M. Health related lifestyle in adolescence predicts adult educational level: A longitudinal study from Finland. J Epidemiol Community Health 1998; 52 (12): 794-801.

9. Karvonen S, Rimpela AH, Rimpela MI. Social mobility and health related behaviours in young people. $J$ Epidemiol Community Health 1999; 53 (4): 211-7.

10. West P. Rethinking the health selection explanation for health inequalities. Soc Sci Med 1991; 32: 373-84.

11. Elstad JI. Employment status and womens health - exploring the dynamics. Acta Sociol 1995; 38 (3): 231-49.

12. Power C, Matthews S, Manor O. Inequalities in self rated health in the 1958 birth cohort: Lifetime social circumstances or social mobility? Br Med J 1996; 313: 449-53.

13. Blane D, Smith GD, Bartley M. Social selection - what does it contribute to social-class differences in health. Sociol Health Illness 1993; 15 (1): 2-15.

14. Lundberg O. Childhood living conditions, health status, and social mobility: A contribution to the health selection debate. Eur Sociol Rev 1991; 7 (2): 149-16.

15. Rahkonen O, Arber S, Lahelma E. Health-related social mobility: A comparison of currently employed men and women in Britain and Finland. Scand J Soc Med 1997; 25 (2): 83-92.

16. van de Mheen HD, Stronks K, Mackenbach JP. A lifecourse perspective on socio-economic inequalities in health: The influence of childhood socio-economic conditions and selection processes. Sociol Health Illness 1998; 20 (5): 754-77.

17. van de Mheen $\mathrm{H}$, et al. The influence of adult ill health on occupational class mobility and mobility out of and into employment in the Netherlands. Soc Sci Med 1999; 49 (4): 509-18.

18. Lindholm C, Burstrom B, Diderichsen F. Does chronic illness cause adverse social and economic consequences among Swedes? Scand J Public Health 2001; 29 (1): 63-70.

19. Claussen B, Bjørndal A, Hjort PF. Health and reemployment in a 2 year follow-up of long-term unemployed. $J$ Epidemiol Community Health 1993; 47 (1): 14-18.

20. Claussen B. Health and re-employment in a five-year follow-up of long-term unemployed. Scand J Public Health 1999; 27 (2): 94-100.

21. Dahl E. Social inequality in health - The role of the healthy worker effect. Soc Sci Med 1993; 36 (8): 1077-86.

22. Rikstrygdeverket. Trygdestatistisk Arbok 1998. Oslo, 1998.

23. Dahl E, Birkelund GE. Sysselsetting, klasse og helse 1980-1995. En analyse av fem norske levekårsundersøkelser. Tidsskrift for samfunnsforskning 1999; 40 (1): 3-32.

24. Bartley M, Owen C. Relation between socioeconomic status, employment, and health during economic change, 1973-93. Br Med J 1996; 313: 445-9.

25. Lissau I, et al. Social differences in illness and health-related exclusion from the labour market in Denmark from 1987 to 1994. Scand J Public Health 2001 (Supplement 55): 19-30.

26. Elstad JI. Health-related mobility, health inequalities and gradient constraint - discussion and results from a Norwegian study. Eur J Public Health 2001; 11 (2): 135-40.

27. Dahl E. Sosial ulikhet i helse: Artefakter eller seleksjon? Oslo: FAFO-Rapport 170, 1994.

28. Bartley M, Plewis I. Does health-selective mobility account for socioeconomic differences in health? Evidence from England and Wales, 1971 to 1991. J Health Soc Behav 1997; 38 (4): 376-86.

29. Whitehead M. The concepts and principles of equity and health. Int J Health Serv 1992; 22 (3): 429-45.

30. Starfield B. Improving equity in health: A research agenda. Int J Health Serv 2001; 31 (3): 545-66.

31. Arbeids- og Administrasjonsdepartementet. Pressemelding 64/2001: Et mer inkluderende arbeidsliv. Oslo: 2001.

32. Dutch Programme Committee on Socio-Economic Inequalities in Health. Reducing Socio-Economic Inequalities in Health. Haag: Ministry of Health, Welfare and Sports, 2001. 